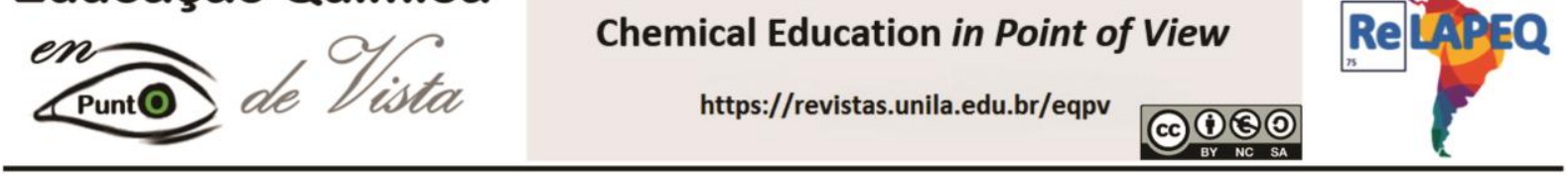

\title{
Experimentando e "Adoçando" o Ensino de Química: das dificuldades em estequiometria à confecção de alfajores
}

\author{
Gustavo Pricinotto ${ }^{1}$, Julia Oliveira Primo ${ }^{2}$ \\ ${ }^{1}$ Doutor em Ensino de Ciências e Educação Matemática pela Universidade Estadual de Londrina. \\ Professor da Universidade Tecnológica Federal do Paraná (UTFPR/Brasil). \\ ${ }^{2}$ Mestra em Química pela Universidade Estadual do Centro-Oeste.
}

\section{Experimenting and "Sweetening" the Teaching of Chemistry: from difficulties in stoichiometry to making alfajores.}

Informações do Artigo

Recebido: $23 / 04 / 2020$

Aceito: $22 / 06 / 2020$

Palavras chave:

três momentos pedagógicos;

formação Inicial docente,

estequiometria

Key words:

three pedagogical moments; initial

teacher training, stoichiometry

E-mail:

gustavopricinotto@gmail.com

\begin{abstract}
A B S T R A C T
Understanding how difficulties for students and teachers in the process of teaching and learning chemistry in the content of stoichiometry is extremely important and long-lasting data, due to large mathematical and memorization entries that students have to deal with, use the most important content and disinterested. After accepting what are the difficulties of those involved, this work proposes the planning and development of a thematic and experimentation workshop, using the works of Delizoicov and Angotti (1990) and applied to students in the second year of high school. The development took place with a questionnaire as a diagnostic evaluation, followed by practical activities, including the making of alfajores and the final dialogue, as a process of validating learning. It was verified as activities in question, what type of organization contributed to the teaching and learning process in a motivating way, articulating scientific knowledge to common and everyday sense.
\end{abstract}

\section{INTRODUÇÃO}

Para que efetivamente consigamos compreender quais as dificuldades apresentadas por estudantes em determinados conceitos e conteúdos, é de extrema importancia que conhecamos a essencia dos mesmos. Neste sentido, ao buscarmos compreender o conceito de estequiometria, somos remetidos a pensar em quando o termo foi introduzido por Richter em 1792, sendo uma palavra de origem grega (stoicheon = elemento e metron = medir), referindo-se a cálculos matemáticos a fim de quantificar a matéria envolvida em um processo químico [56-201 e R0798]. Sendo que, a estequiometria está baseada 


\section{Educação Química}

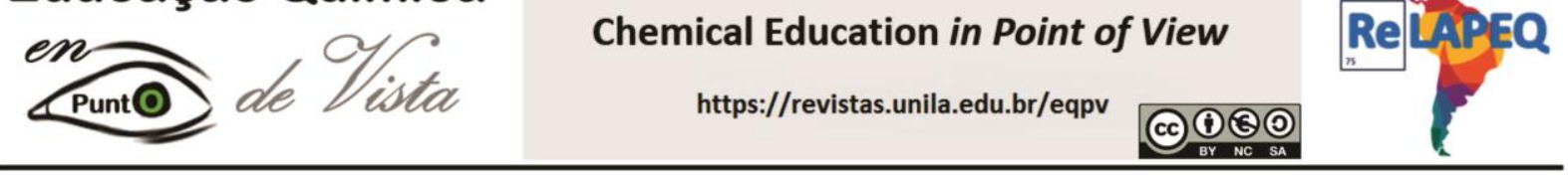

principalmente em duas leis ponderais, na lei da conservação das massas, anunciada como "[...] a soma das massas dos reagentes é sempre igual à soma das massas dos produtos" (LAVOISIER, 1785 apud CAZZARO, 1999) e na lei das proporções fixas "[...] uma substância qualquer que seja sua origem, apresenta sempre a mesma composição em massa" (PROUST, 1799 apud CAZZARO, 1999).

Em se tratando do ensino de Química, na grande maioria das vezes o tema é abordado de forma descontextualizada, isolada, mesmo que o tema permeia muitos conteúdos, contextos e cotidiano dos estudantes dentro da perspectiva química, principalmente quando a temática em questão aborda assuntos relacionados a quantidades de matéria e número de mols (FURIÓ et al., 2000; COSTA;SOUZA 2013), ainda segundo os autores, muitas pesquisas apontam dificuldade tanto dos estudantes na compreensão do conceito, quanto dos professores em buscar métodos e recursos adequados para desenvolver e associar o tema ao cotidiano dos estudantes (COSTA; ZORZI, 2008).

Em trabalho desenvolvido no Estado do Paraná por Costa e Zorzi (2008) junto as escolas Estadual do Núcleo de Ensino de Maringá, observaram-se que a estequiometria representa o conteúdo de maior dificuldade de assimilação pelos estudantes, quando em resposta a esta pesquisa, os professores elegeram este tema como o mais difícil de aprender (Costa e Zorzi, 2008). Dentre as razões que podemos justificar esta dificuldade, alguns autores (CAZZARO, 1999; ANDRADE, 2018) destacam que a aprendizagem do cálculo estequiométrico envolve uma série de habilidades, tais como: raciocínio proporcional, aritméticas, da conceituação de reações química, da conceituação de mol, massas molares e principalmente da interpretação da equação química.

Essas dificuldades apresentadas podem ser compreendidas inicialmente pela falta de contextualização dos conteúdos com a realidade dos estudantes, mas também estar relacionadas diretamente a falta de recursos e a superficialidade da formação dos professores da Educação Básica, que muitas vezes tem capacitação aquém das necessidades escolares. Por este motivo, muitas vezes o ensino se torna massante, em que o conteúdo de estequiometria é abordado de forma isolada, sem qualquer relação com o cotidiano do aluno, seguida de exercícios de fixação, valorizando um processo de memorização que não contribui para um processo de aprendizagem dos estudantes. O tema é normalmente reduzido às fórmulas matemáticas e à aplicação de "regras", que devem ser exaustivamente repetidas e seguidas, tornando o conhecimento sem "sentido", desvinculado-o de realidades, não sendo associado o conhecimento químico aos problemas e informações advindas do cotidiano. Neste sentido, fazemos a seguinte provocação, que irá guiar os direcionamentos do trabalho aqui apresentado: como podemos articular estequiometria às situações corriqueiras do dia a dia dos estudantes, contribuindo assim para a formação cidadã dos estudantes? 


\section{Educação Química}

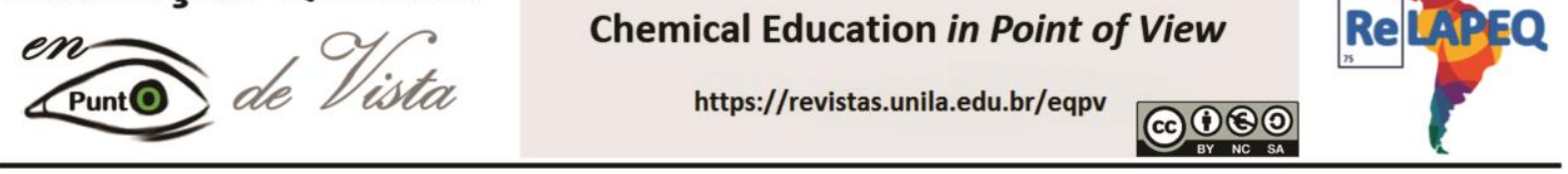

Acreditamos que a potencialidade desse questionamento está em fazer refletir todos os sujeitos que buscam superar a barreira da memorização que normalmente é utilizada no Ensino de Química, abrindo espaços para pensar: que estudante quero formar? Quais possibilidades de problematização estou criando para meus estudantes? Por fim, apresentaremos alguns caminhos, através de uma oficina, que nos possibilite repensar o ensino dogmatizado de estequiometria.

\section{METODOLOGIA}

A atividade desenvolvida foi planejada, colocada em prática e avaliada, como proposta da disciplina de Estágio Supervisionado 3, que visa desenvolver feiras de ciências nas escolas da rede pública da Cidade de Campo Mourão, e foi aplicada em duas turmas da 2a Série do Ensino Médio de uma escola pública, o Colégio Estadual Prefeito Antônio Teodoro de Oliveira. As turmas em questão foram selecionadas devido as angustias da professora regente, que constantemente questionava e apontava suas dificuldades quanto a apresentação do conteúdo de cálculo estequiométrico. O número total de estudantes participantes da atividade foi de cinquenta e quatro estudantes (54).

Diante do que foi proposto na disciplina, deveriamos desenvolver atividades experimentais com viés de "feira de ciências", com o intuito de interessar e motivar os estudantes a aproximarem seus conhecimentos e problemas rotineiros aos conhecimentos científicos, em um processo de rearticulaçaõ dos conhcimentos. Por este motivo, o trabalho realizado com essas turmas foi baseado na criação de oficinas temáticas e da experimentação, seguindo os pressupostos do trabalho de Delizoicov e Angotti (1990), e teve como objetivo geral a aplicação de um método de ensino diferenciado, despertando motivação e curiosidade no aluno, frente a situações do cotidiano referentes ao estudo do cálculo estequiométrico.

A oficina temática foi intitulada de "Receitas de casa: quantidades e matérias". O conteúdo foi escolhido devido à dificuldade tanto do aluno em aprender e resolver problemas que envolvem cálculos estequiométricos, quanto dos professores em associar o tema com o cotidiano, por ser um tema que envolve cálculos matemáticos e muitas vezes é visto como distanciado aos problemas reais vivenciados. A oficina temática foi desenvolvida em um período de 3 horas/aula em cada turma.

$\mathrm{Na}$ primeira aula, foi desenvolvido o primeiro momento pedagógico da oficina temática, que, segundo Delizoicov e Angotti (1990), é chamado de problematização inicial, e procedeu-se da aplicação de um questionário prévio, momento este que visou identificar o conhecimento dos alunos acerca da temática trabalhada junto a um processo de investigação e problematização por meio de experimentação, levando o aluno a criar hipóteses. 0 questionário foi aplicado na semana anterior à realização da prática sobre estequiometria e era composto por quatro questões. 


\section{Educação Química}
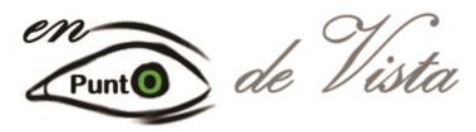

\section{Chemical Education in Point of View}

https://revistas.unila.edu.br/eqpv

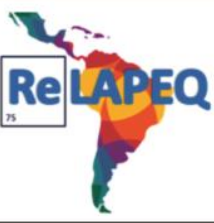

$\mathrm{Na}$ segunda aula foram desenvolvidas duas experiências, ainda trabalhando a problematização inicial. O primeiro experimento realizado foi para trabalhar a Lei das Conservações das Massas de Lavoisier, em que grupos foram formados a fim de observar se as massas realmente se conservam ao submeter um material ao um processo químico, nesse caso um processo simples de combustão. Assim, balanças feitas com materiais alternativos foram confeccionadas (Figura 1 ) e distribuídas para os 5 grupos formados. E foram expostos articulados a seguinte situação problema:

Lavoisier é conhecido pela seguinte frase: Na natureza nada se cria, nada se perde, tudo se transforma. Pensando na Lei das Conservações das Massas, você coloca a mesma quantidade de papel em ambos os lados da balança e colocar fogo em um dos pedaços de papel (Figura 2a), observa e anote suas conclusões, ainda não satisfeito você decide queimar outro material a lã de aço, seguindo o mesmo processo anterior (Figura 2b), anotando-se as conclusões.

Figura 1 - Balança confeccionada com materiais alternativos para aplicação da oficina.

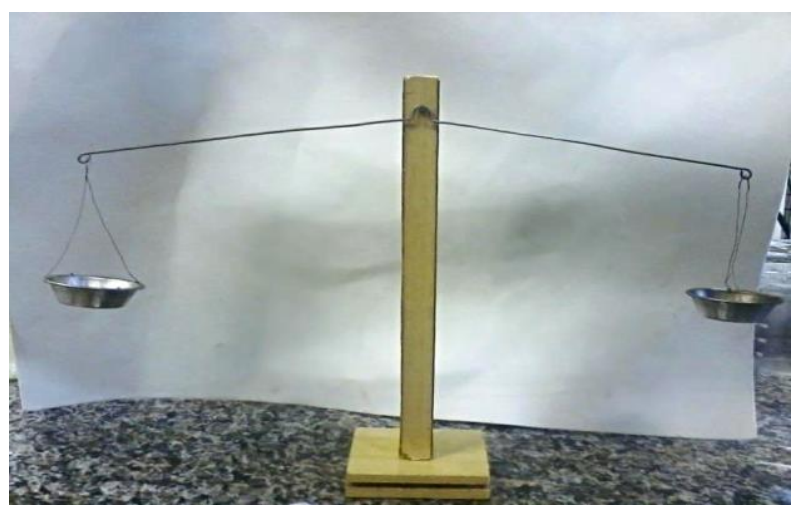

Fonte: dos autores.

Figura 2 - Experimento Conservações das Massas, observação da queima: (a) papel; (b) lã de aço.

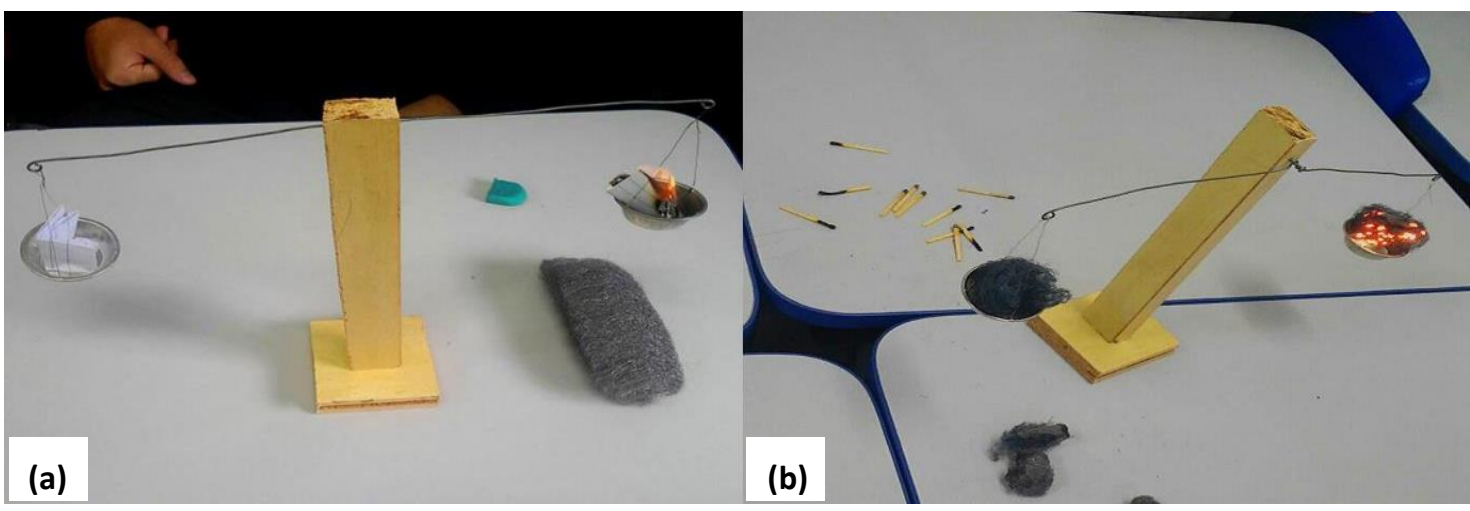

Fonte: dos autores. 


\section{Educação Química}
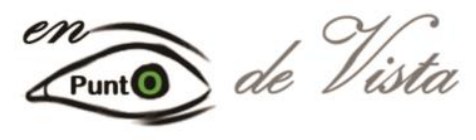

Chemical Education in Point of View

https://revistas.unila.edu.br/eqpv

Após a experiência, foi realizada uma discussão sobre os conceitos referentes ao tema com os alunos, juntamente com um segundo experimento, que consistia em discutir conceitos referentes a reagentes limitantes e em excesso. $O$ experimento é realizado com a adição de mesma proporção de bicarbonato de sódio dentro de recipientes (garrafa pet), porém contendo proporções distintas de vinagre, ocorrendo em seguida à liberação de gás que é aprisionado por uma bexiga (Figura 3). Como a elaboração da atividade ocorreu diante dos olhos dos estudantes, alguns deles prontamente afirmaram que a quantidade de gás que enchia a bexiga era diretamente proporcional a quantidade de "pó" e líquido que estavam dentro dos recipientes.

As afirmativas, neste sentido, podem ser observadas durante e após a realização dos experimentos, que foram discutidos com os alunos, levantando hipóteses e trabalhando conceitos sobre o conteúdo (mol, quantidade de matéria, proporção, massa, conservação de massa etc) e relacionando com os experimentos.

Figura 3 - Experimento proposto a fim de discutir acerca de reagente limitante e em excesso.

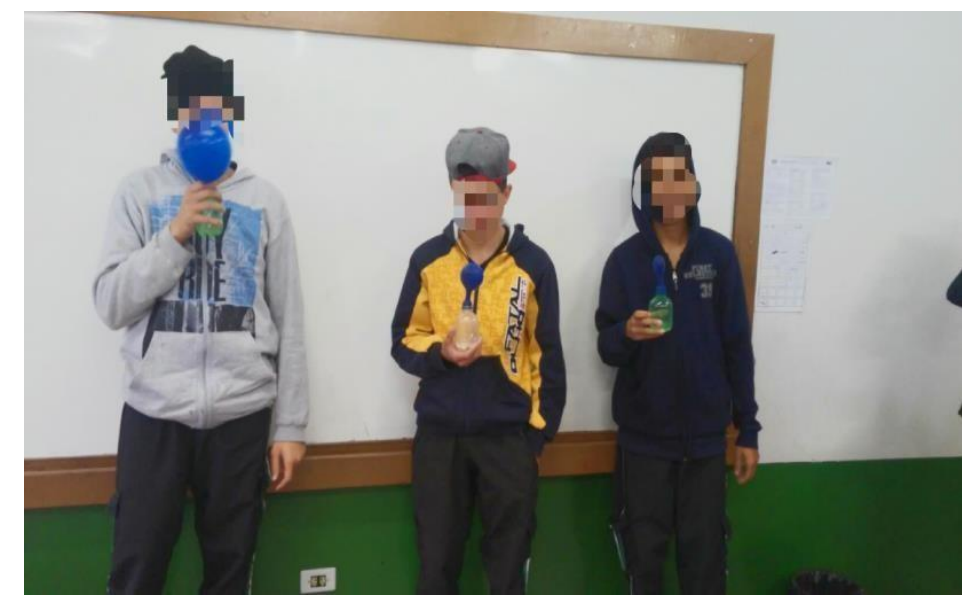

Fonte: dos autores.

Importante salientar que as atividades experimentais somente foram possíveis de compreensão por parte dos estudantes quando articuladas, pois os conceitos só poderiam ser compreendidos em sua completude, se discutidos no conjunto das duas atividades, visando assim, uma organização do conhecimento dos estudantes, que segundo Muenchen e Delizoicov (2011), seria o segundo momento pedagógico, que apresentamos na sequência.

Na terceira e última aula, realizou-se a confecção de alfajores, como metodologia para que os alunos pudessem organizar seus conhecimentos previamente trabalhados nos experimentos anteriores, este é o segundo momento segundo Muenchen e Delizoicov (2011), a organização do conhecimento. Com a confecção, os alunos são postos diante de questionamentos referentes à lógica para calcularem o rendimento e proporção de reações. Neste momento, os alunos que se encontravam em grupos receberam uma tabela em que 


\section{Educação Química}

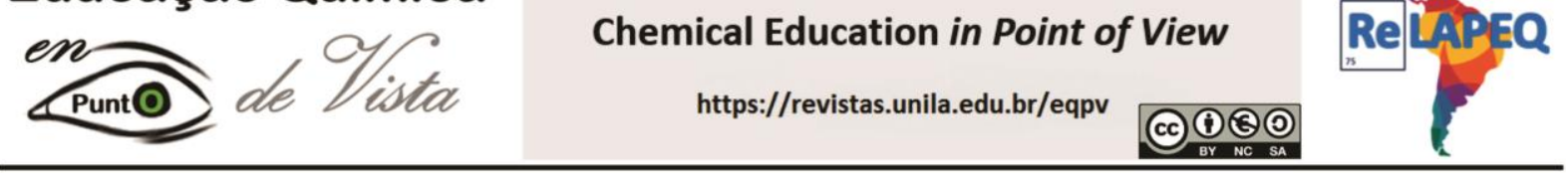

cada grupo tinha a receita para a confecção de um alfajores, porém cada grupo tinha uma proporção para ser solucionada, assim colocando em prática o conhecimento adquirido no experimento anterior.

Inicialmente os estudantes, a partir de seus conhecimentos prévios, conseguiram confeccionar os alfajores sem maiores dificuldades, seguindo as experiencias que já haviam vivenciado quanto a terem se alimentado de tal produto. O que nos pareceu interessante, foi que, ao se depararem com a quantidade de reagentes (ingredientes para produzirem os alfajores), principalmente a quantidade de bolacha, alguns grupos conseguiram compreender que a quantidade total produzida não seria suficiente para o grupo $A$, questionando a professora regente neste momento: "prof, o tanto que tem de bolacha aqui não da pra fazer um pra cada!", e que prontamente foi realizada uma discussão sobre o conceito de reagente limitante, e que antes mesmo que pudesse ser extrapolado para o conceito de reagente em excesso, como proposto em plano de aula, outro estudante do grupo C fez a seguinte afirmativa: "nois (sic) temos sobrando, vai dar pra comer mais que um pra cada".

Desde modo, a regente pode discutir com os estudantes os dois conceitos, articulando conceitos científicos e conhecimento prévio, de quantidade, proporcionalidade e divisão matemática. Neste momento, os estudantes conseguiram compreender que para a produção de determinadas quantidades (produtos) há uma proporcionalidade de reagentes que devem ser consumidos, e assim sendo, toda reação partilha dessa demanda. Por fim, os estudantes tiveram de, unindo todos os grupos, tiveram de montar a tabela em conjunto na lousa, para que pudessem compreender que as "sobras" de alfajores do grupo $C$, eram exatamente as quantidades faltantes do grupo $A$, sendo que o grupo $B$ tinha quantidade exata de proporção referente a reação em questão de produção de alfajores. A atividade possibilitou aos estudantes uma reorganização dos seus conhecimentos prévios, agora remanejados e rearticulados sob um viés dos conceitos científicos.

Por fim, na última atividade, nomeada pelos autores como "aplicação do conhecimento", que foi desenvolvida no final da aula, momento pedagógico este em que se analisa e interpreta as situações iniciais trazidas pelo professor, apresentando aos estudantes novas situações problemas. Realizando assim uma retomada e rearticulaçao dos momentos da aula. Acreditamos que todo o processo sendo realizado de forma dialogada potencializa a proposta de Delizoicov e Angotti (1990), por este motivo, diferente do que apresentam outros trabalhos que se amparam neste perspectiva, sinalizamos que os momentos pedagógicos devem ser articulados junto a problemática e um tema gerador, como apontaria Paulo Freire (1984), sem que estes parecam sem contexto aos estudantes, para que se tenha uma construção do conhecimento de forma crítica e reflexiva, tanto para os estudantes, quanto os professores. 


\section{Educação Química}
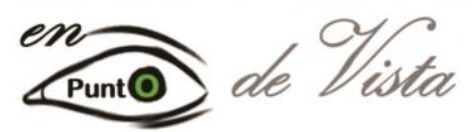

Chemical Education in Point of View

https://revistas.unila.edu.br/eqpv

\section{RESULTADOS E DISCUSSÕES}

A avaliação da metodologia aplicada se deu com a aplicação de um Questionário Inicial (QI) e nas respostas das questões apresentadas pelos estudantes em sala de aula, através da observação do emprego dos conceitos, da articulação que cada um fez para explicar os problemas que lhe foram expostos, tudo isso com o intuito de investigar se os alunos compreenderam os conceitos e se conseguiriam aplicá-los em diferentes situações, relacionando-os com seu cotidiano, e tomando as possíveis decisões diante das dificuldades.

Para a compreensão destes resultados almejados, buscando analisar cada uma das questões articulando-as aos comentários apresentados pelos estudantes, buscando assim, uma análise detalhada dos possíveis caminhos desenvolvidos pelos alunos. Nesse sentido, ao analisarmos a primeira questão do Ql que tratava da opinião do aluno quanto a sua dificuldade em cálculo estequiométrico, foi possível observar que mais de $50 \%$ dos alunos apresentavam algum tipo de dificuldade quanto ao conteúdo, sendo a principal delas o argumento de que não compreendiam o conceito de balanceamento de reacões. Isso também pode ser notado ao iniciamos as atividades experimentais, em que os estudantes tiveram de fazer o balanceamento das reações da segunda etapa, e os mesmos não conseguiam, mesmo com os processos norteadores apresentados durante a atividade.

Gráfico 1 - Respostas apresentadas à questão 1 do questionário inicial.

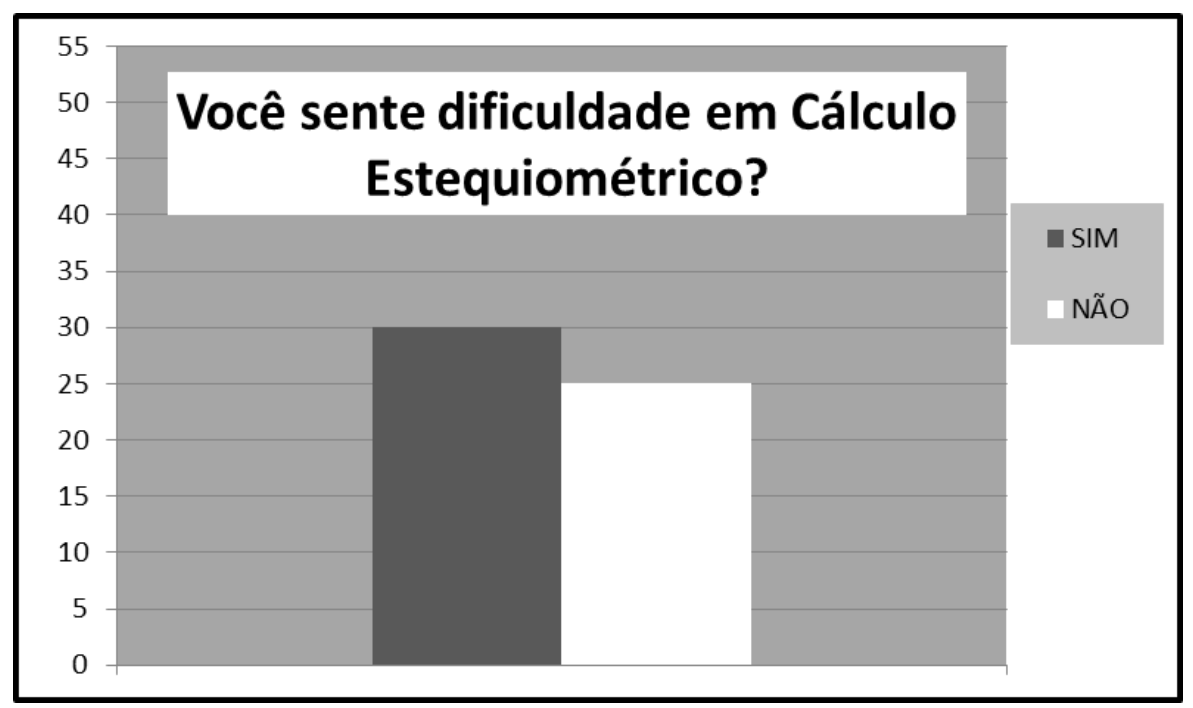

Fonte: dos autores.

Veremos adiante, que neste momento, a falta apresentada pelos estudantes estava diretamente relacionada a falta de conscientização, no sentido apresentado por Paulo Freire (1980) ao afirmar em sua pedagogia libertadora, que a educação é um ato de conhecer, de 


\section{Educação Química}
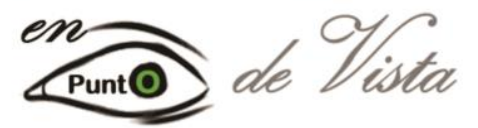

Chemical Education in Point of View

https://revistas.unila.edu.br/eqpv

aproximar conceitos a realidade. Para os estudantes, muitas vezes apresentados a fórmulas e equações a serem memorizadas pouco ou nada compreendiam da sua realidade, do cotidiano e contexto em que estavam imersos, e por este motivo, distanciavam-se do conteúdo de estequiometria, e tornavam-no algo de difícil compreensão.

Em outra questão, dos 54 alunos que responderam o questionário, 65,4\% acreditam que a Estequiometria tem aplicação no cotidiano (Gráfico 2), porem informam que nunca foram apresentados a estas relações, ou quando muito, são apresentados a modos de exemplificação, sem um processo de discussão referente a sua compreensão. Nesse sentido, é importante salientar que a mera exemplificação, se pararmos para observar os dados, não deixa de ser uma porcentagem significativamente promissora, pois muitos conseguem relacionar a estequiometria com o cotidiano, como quando os estudantes citam em sala de aula a produção de bolos, principalmente quando tratávamos da temática referente as proporções fixas de Proust, da importância da proporcionalidade em uma determinada aplicação.

Gráfico 2 - Respostas apresentadas à questão 2 do questionário inicial.

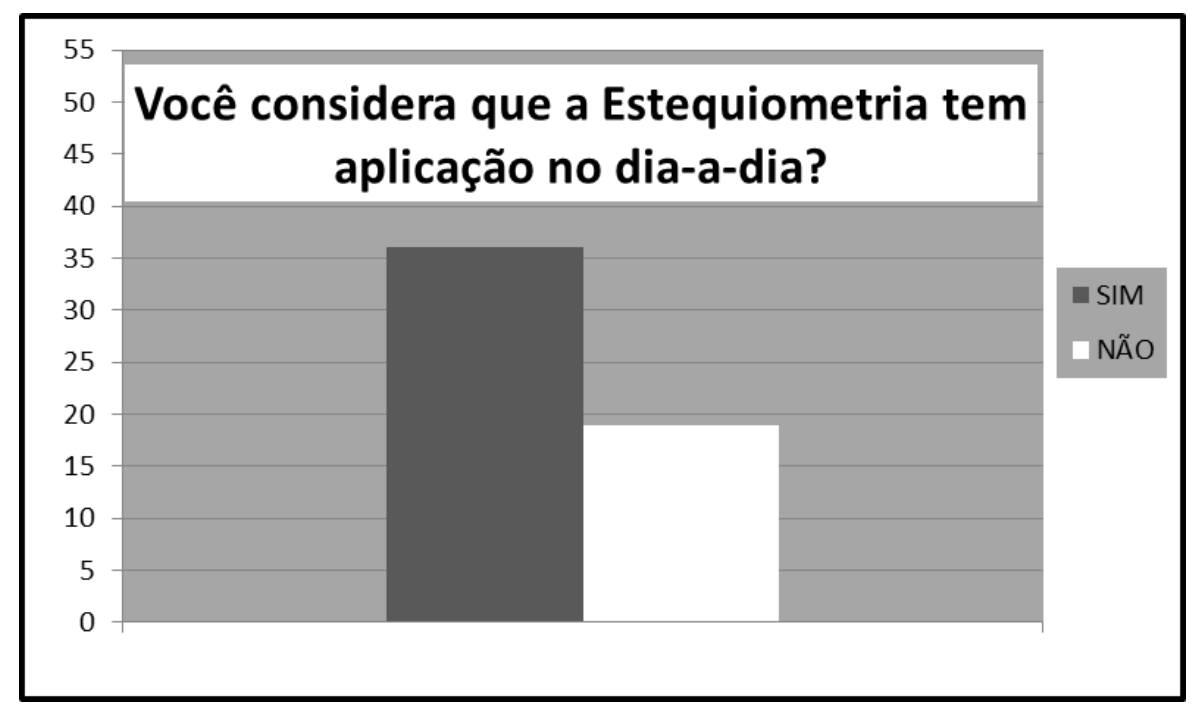

Fonte: dos autores.

Assim sendo, cabe a nós professores, usarmos destes conhecimentos e relaciona-los com o cotidiano de maneira que possamos levar o aluno a atingir uma aprendizagem significativa, por meio de tomadas de decisões e da formação cidadã, e não apenas usarmos de meras exemplificações e trabalhar a Química de uma forma superficial e descontextualizada. Devem-se buscar temas geradores sobre assuntos do cotidiano no qual o conhecimento científico seja capaz de atender às muitas dúvidas que possam surgir (PEIXOTO, 1999). 


\section{Educação Química}

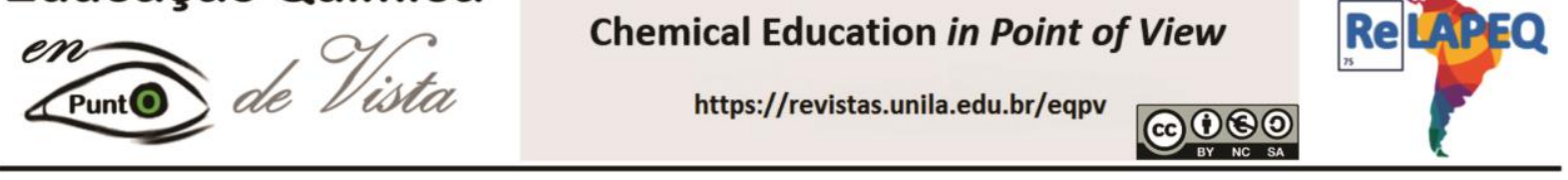

Articulando as dificuldades apresentadas na primeira questão, e a credibilidade, e potencialidade do conteúdo de cálculo estequiométrico apresentado pelos estudantes na segunda, na terceira questão, visamos compreender o nível de dificuldade de conhecimento básico dos estudantes, quando questionados sobre uma grande dificuldade apresentada por alunos quanto a confusão de termos muito utilizados e muitas vezes difundidos de forma equivocada em Química, principalmente quando se trabalha cálculo estequiométrico, que é mol, quantidade de matéria e massa molar. Apresentado que mol é uma unidade de medida da quantidade de matéria e não a própria quantidade de matéria. Segundo a IUPAC (União Internacional de Química Pura e Aplicada) mol deve ser definido como unidade de medida do Sistema Internacional que mede a grandeza física quantidade de matéria.

Nota-se diante das respostas, que mesmo com toda a credibilidade data ao conteúdo de cálculo estequiométrico, os estudantes têm dificuldades quanto a compreensão de alguns conceitos prévios necessários para a compreensão do conteúdo, o que pode nos levar a questionarmos a problemática quanto ao conteúdo de estequiometria, tendo ainda que pesquisarmos sobre as dificuldades apresentadas anteriormente quanto aos conhecimentos prévios dos estudantes. Isso pode ser afirmado, pois, alguns estudantes chegam a afirmar que matéria e mol significam a mesma coisa, percebendo-se que o motivo que muitos não compreendem o conteúdo de estequiometria devido à falta de compreensão do básico, como simples conceitos químicos.

A questão 4 tratava de uma situação do cotidiano do aluno, o corte de uma cebola para preparação de um jantar. Nesta questão o aluno teria que interpretar a questão e explicar quimicamente por que choramos ao cortarmos cebola. A busca por compreender situações reais e cotidianas, levaram muitos estudantes (aproximadamente 50\%) a reescreverem a questão que vos foi apresentada, demonstrando dificuldade para articular o cotidiano as questões técnicas e científicas, o que pode evidenciar uma defasagem quanto a este processo de contextualização e articulação por parte dos alunos.

Quanto as demais respostas seguiram uma mesma proposta: a de apresentar como ocorre a reação entre o ácido e o processo de lacrimação em contato com o olho. A partir disso, podemos desmembrar as soluções em dois "caminhos" distintos: os estudantes que explicaram que há um contato e uma reação, e os que conseguiram efetivamente elaborar a reação química e definir quem seriam as substâncias no processo. Diante do exposto por escrito pelos estudantes, muitas dúvidas foram deixadas, e posteriormente foram discutidas, sendo que em diversos momentos os estudantes diziam que "só sabiam a realidade, mas não a Química", como se houvesse um desmembramento entre eles, como se possível compreender o mundo, sem a Química, ou vice e versa. Compreender este (im)possível distanciamento é de extrema importante para nós professores que buscamos uma formação diferenciada e de caráter formativo de um cidadão crítico, pois somente deste modo, conseguiremos rearticula-lo e daremos voz aos estudantes que muitas vezes são silenciados, 


\section{Educação Química}

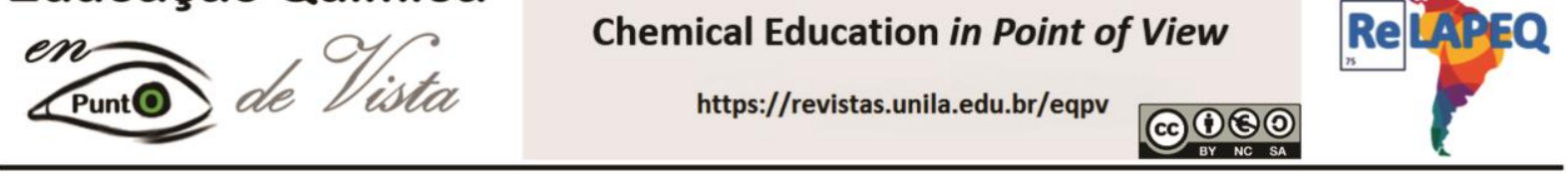

somente por não falarem "como químicos", dentro de um parâmetro excludente curricular científico.

Compreender as dimensões que rondam a fase inicial do processo diagnostico de conhecimento prévio dos estudantes é importante para que os próximos passos dos três momentos sejam (re)planejados - devido às necessidades apresentadas inicialmente as atividades são sempre adaptadas - e desenvolvidas com o intuito de iniciar ou reorganizar o processo de ensino e aprendizagem do conceito de cálculo estequiométrico. Tendo em vista as diversas dificuldades apresentadas e dialogadas anteriormente, e a fim de avaliar o resultado final da oficina trabalhada, buscamos realizar uma análise dos dados por meio das atividades desenvolvidas nas relações entre os estudantes e na conexão destes com professor, acreditamos que neste contexto seja mais vantajoso o processo de avaliação da oficina, por meio de uma análise primordial das discussões e atividades desenvolvidas em sala de aula. Pensamos deste modo, pois ao acompanharmos uma avaliação enquanto formativa, seja mais precisa para este momento, do que sob uma perspectiva somativa, pontual e isolada.

A avaliação da aplicação da oficina desenvolveu-se dentro de vários aspectos, tendo início na confecção dos alfajores, em que os alunos tiveram que executar cálculos diferentes entre os grupos, diante de problemáticas distintas, em que estes deveriam propor novas hipóteses e tomarem suas possíveis decisões, precisando para a resolução que tivessem compreendido as primeiras atividades experimentais, assim como se auxiliarem através de raciocínio lógico e interpretação dos dados. Assim, cada grupo com a tabela com a receita da confecção de um alfajor, tinha que calcular quantidade final de alfajor (produto) e de ingredientes (reagentes) dadas em diferentes proporções para cada grupo, necessitando para isso, que compreendessem alguns conceitos anteriormente aplicados na problematização inicial e organização do conhecimento.

A evolução desenvolvida pelos estudantes entre a passagem das primeiras atividades experimentais, e na questão 4 do questionário diagnóstico, para o momento da aplicação do conhecimento foi notória, pois os erros anteriormente cometidos foram sanados de forma satisfatória, possibilitando aos estudantes, em grupos, argumentarem e tomarem decisões pertinentes quanto aos passos a serem desenvolvidos para a confecção dos alfajores, inclusive, discutindo com os mesmos, questões referentes aos reagentes limitantes e em excesso das reações, na relação com o cotidiano e descarte excessivo de alimentos que fazemos diariamente.

Este processo, como anteriormente exposto, caracterizou-se extremamente importante pois nele pudemos evidenciar uma ressignificação de informações previamente estabelecidas pelos estudantes, agora articuladas a conceitos científicos, tanto no que se referente aos reagentes limitantes e em excesso, quanto aos processos de conservação de massas e proporcionalidade. Neste processo de reformulação e rearticulação de 


\section{Educação Química}

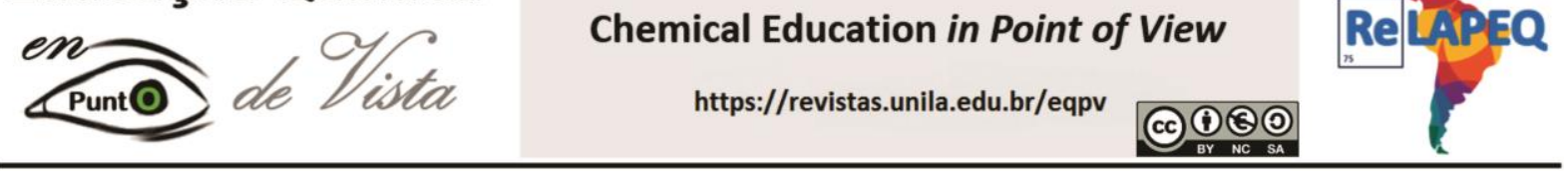

conhecimentos, notamos a evolução entre as etapas dos momentos pedagógicos, em que os estudantes conseguiram sanar diversas dúvidas quanto aos conceitos, cálculos e cotidiano, anteriormente não compreendidos.

\section{CONSIDERAÇÕES FINAIS}

Sanar as dificuldades apresentadas pelos estudantes e professores deve ser o catalizador para o desenvolvimento de pesquisas nas perspectivas do Ensino de Ciências e Química, e foi com este objetivo que buscamos compreender quais as limitações e dificuldades dos alunos e docentes quanto ao processo de ensino e aprendizagem sobre o conteúdo de estequiometria. Mesmo com todas as contingências do desenvolvimento da pesquisa, os resultados obtidos por meio da oficina realizada foram muito interessantes e potentes, e por este motivo acreditamos na potencialidade do que aqui foi exposto.

Porém, ainda há muitas razões para desejarmos uma aprendizagem química mais crítica por parte dos alunos, permitindo que os indivíduos se integrem à sociedade de forma mais ativa e consciente. Segundo Gomes e Macedo (2007), com o conhecimento científico à sua disposição, cada indivíduo atua de forma específica sobre a natureza, modificando-a e modificando-se, segundo as teses do pensamento dialético. Porém, diante dos parametros atuais de cumprirmos com ementas extensas e curriculos tradicionais de ensino, atentamonos mais potentemente em cumprirmos com às exigências das provas de vestibulares e demais avaliações para ingresso nas universidades, partilhando assim de que o ensino de Química, dentro dos moldes atuais, ainda esta muito longe do que se deseja ao pensar em propostas que contemplem as necessidades básicas presentes no cotidiano de nossos alunos (GOMES; MACEDO, 2007).

Diante das dificuldades apresentadas ao longo do trabalho, notamos que a elaboração e execução de oficinas temáticas, por meio dos três momentos pedagógicos sugeridos por Delizoicov e Angotti (1990), a problematização inicial, a organização e aplicação do conhecimento, possibilitou-nos o desenvolvimento de um trabalho levando em consideração a contextualização do conteúdo de cálculo estequiométrico com as informações rotineiras dos estudantes, contribuindo para a reformulação da formação inicial docente, e de cidadãos críticos em sala de aula. Compreendemos que a dificuldade dos professores em realizar essa articulação está presente devido a formações superficiais e muitas vezes técnicas, tendo que muitas vezes desenvolverem atividades distantes da realidade dos estudantes, mas é necessário que façamos com que a aprendizagem do estudantes tenha "sentido" nas coisas que aprende, relacionando conhecimento científico e aplicações para o seu dia-a-dia.

Tendo em vista a dificuldade desta articulação, seja por parte dos professores, tanto quanto dos estudantes, a aplicação da oficina teve méritos enquanto estratégia utilizada 


\section{Educação Química}
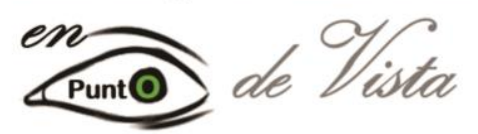

Chemical Education in Point of View

https://revistas.unila.edu.br/eqpv

para propor e colocar em prática uma aprendizagem que não estimula o aluno a decorar fórmulas, sem significado algum para o estudante, além de ser um meio de se trabalhar o conteúdo de forma mais participativa e dinâmica e com a interação de fatos do cotidiano nas discussões em sala de aula. Sendo um dos motivos da escolha deste conteúdo, por se utilizar tanto de cálculos matemáticos ligados a interpretação de problemas trabalhados de forma "mecanizada", aumentando a dificuldade de compreensão em cálculo estequiométrico.

Buscando a articulação do cotidiano com o conteúdo, ainda é válido destacar, que os estudantes apresentaram grande avanço quanto a capacidade de compreenção e facilidade para propor relações de tomada de decisão diante dos problemas criados, mas nota-se ainda, uma defasagem quanto aos conteúdos competentes a disciplina de Matemática, principalmente no que tange a operações básicas, observando assim que é importante identificar estas falhas para que em futuras aplicações possam ser solucionados os problemas com antencedencia, em um processo de rearticulação dos conhecimentos prévios necessários.

\section{REFERÊNCIAS}

AMARAL, L. O. F. Reações Químicas, Proporções Definidas \& Cálculo Estequiométrico: Uma Discussão Sobre Ensino. Belo Horizonte: publicação interna do Departamento de Química da UFMG, 1997.

ANDRADE, L. M. Uma Proposta de Abordagem no Ensino de Cálculo Estequiométrico para o Ensino de Química Básica. Trabalho de conclusão de curso. Instituto Federal Goiano. 2018.

CASTILHO, D. L., SILVEIRA, K. P., MACHADO, A. H. As aulas de química como espaço de investigação e reflexão. Química Nova na Escola, n. 9, p. 15-17, 1999.

CAZZARO, F. Um experimento envolvendo estequiometria. Química Nova na Escola, n. 10, nov., p. 53-54, 1999.

COSTA, A.A.F.; SOUZA, J.R.T. Obstáculos no processo de ensino e aprendizagem de cálculo estequiométrico. Amazônia: revista de Educação em Ciências e Matemática. ISSN 19805128. v. 10, n. 19, 2013.

COSTA, E.T.H.; ZORZI, M.B. Uma proposta diferenciada de ensino para o estudo da estequiometria. Produção Didático-Pedagógico. SEEPR, 2008. 


\section{Educação Química}
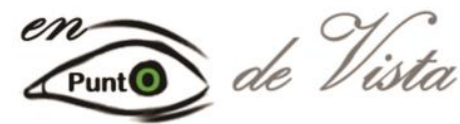

Chemical Education in Point of View

https://revistas.unila.edu.br/eqpv

DELIZOICOV, D.; ANGOTTI, J.A.A. Metodologia do ensino de ciências. São Paulo: Cortez, 1990.

MUENCHEN, C. DELIZOICOV, D. Os três momentos pedagógicos na edição de livros didáticos. Ensino de Ciências e Tecnologia em Revista - ENCITEC, v. 1, n. 1. 2011.

FARIAS, Carlos V. Para compreender a abordagem cognitivista de David Ausubel para o ensino. Disponível em:<www.ufv.br/dpe/edu660/textos/t10_cognitivismo.doc $>$. Acesso em: 24 nov. 2015.

FREIRE, P. Pedagogia do Oprimido.Rio de Janeiro: Paz e terra, 1984.

FURIÓ, C., AZCONA, R., GUISASOLA, J. Revisión de investigaciones sobre la enseñanzaaprendizaje de los conceptos cantidad de sustancia y mol. Enseñanza de las Ciências, v. 20, n. 2, p. 229-242, 2002.

GOMES, R.S.; MACEDO, S.H. Cálculo estequiométrico: o terror nas aulas de Química. VÉRTICES, v. 9, n. 1/3, jan./dez. 2007.

MIGLIATO, J.R.F. Utilização de Modelos Moleculares no Ensino de Estequiometria para alunos do Ensino Médio- Estequiometria - São Carlos (2005), Dissertação de Mestrado UFSCar.

PEIXOTO, D. P. Ensino de Química e Cotidiano. Publicado em maio/1999. Disponível em: http://www.moderna.com.br/artigos/quimica/0025. Acesso em: 24 nov. 2015.

SANTOS, L.C; SILVA, M.G.L. O estado da arte sobre estequiometria: dificuldades de aprendizagem e estratégias de ensino. IX Congreso Internacional sobre Investigación en Didáctica de las Ciencias, 2013.

SILVA, R. R., Filho, R. C. R. MOL: uma nova terminologia. Química Nova na Escola, n. 1, p. 1214, 1995.

TRISTÃO, J. C.; SILVA, G. F.; JUSTI, R. S. Estequiometria: Investigações em uma Sala de Aula Prática. XIV Encontro Nacional de Ensino de Química (XIV ENEQ). UFPR, 21 a 24 de julho de 2008. Curitiba/PR. 


\section{Educação Química}

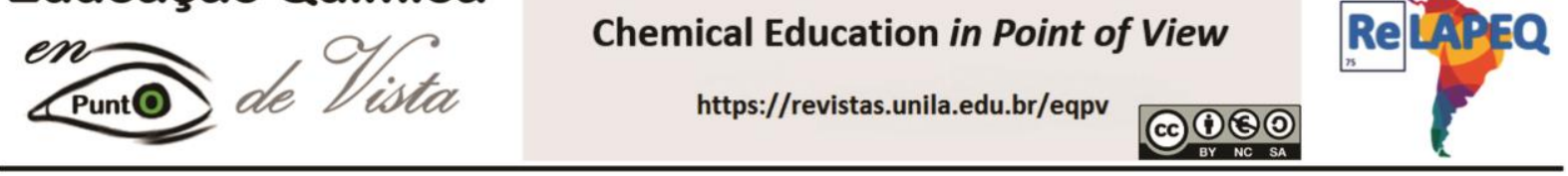

\section{RESUMO}

Compreender as dificuldades apresentadas por estudantes e professores, no processo de ensino e aprendizagem de Química no conteúdo de Estequiometria é de extrema importância e de longa data, devido aos grandes entraves matemáticos e de memorização que os estudantes tem de lidar, tornando o conteúdo maçante e desinteressado. Após inicialmente compreender quais as dificuldades dos sujeitos envolvidos, este trabalho propôs o planejamento e desenvolvimento de uma oficina temática e da experimentação baseada nos trabalhos de Delizoicov e Angotti (1990) e aplicada aos alunos do segundo ano do ensino médio. O desenvolvimento deu-se inicialmente por um questionário como avaliação diagnóstica, seguido de atividades práticas, incluindo a confecção de alfajores e o diálogo final, como processo de validação da aprendizagem. Verificou-se com as atividades em questão, que este tipo de organização contribuiu para o processo de ensino e aprendizagem de forma motivadora, articulando o conhecimento científico ao de senso comum e cotidiano.

\section{RESÚMEN}

Comprender cómo las dificultades para los estudiantes y maestros en el proceso de enseñanza y aprendizaje de la química en el contenido de la estequiometría son datos extremadamente importantes y duraderos, debido a las grandes entradas matemáticas y de memorización con las que los estudiantes tienen que lidiar, usan el contenido más importante y desinteresado Después de aceptar cuáles son las dificultades de los involucrados, este trabajo propone la planificación y el desarrollo de un taller temático y de experimentación, utilizando los trabajos de Delizoicov y Angotti (1990) y aplicado a los estudiantes en el segundo año de la escuela secundaria. El desarrollo se realizó con un cuestionario como evaluación diagnóstica, seguido de actividades prácticas, incluida la elaboración de alfajores y el diálogo final, como un proceso de validación del aprendizaje. Se verificó como actividades en cuestión, qué tipo de organización contribuyó al proceso de enseñanza y aprendizaje de forma motivadora, articulando el conocimiento científico al sentido común y cotidiano. 